\title{
Article \\ Improvement of PMMA Dental Matrix Performance by Addition of Titanium Dioxide Nanoparticles and Clay Nanotubes
}

\author{
Mariafrancesca Cascione ${ }^{1, *(\mathbb{D})}$, Valeria De Matteis ${ }^{1, *(\mathbb{D})}$, Paolo Pellegrino ${ }^{1}$ (D) Giovanni Albanese ${ }^{2,3}$, \\ Maria Luisa De Giorgi ${ }^{1} \mathbb{D}$, Fabio Paladini ${ }^{1}$, Massimo Corsalini ${ }^{3}{ }^{\mathbb{D}}$ and Rosaria Rinaldi $^{1}(\mathbb{D})$
}

1 Department of Mathematics and Physics "Ennio De Giorgi", University of Salento, 73100 Lecce, Italy; paolopellegrino@unisalento.it (P.P.); marialuisa.degiorgi@unisalento.it (M.L.D.G.); fabio.paladini@le.infn.it (F.P.); ross.rinaldi@unisalento.it (R.R.)

2 U.O.C. of Plastic Surgery and Burns Center, Department of Oral Hygiene Clinic, Hospital "A. Perrino", 72100 Brindisi, Italy; giannialbanese69@libero.it

3 Dental School, Interdisciplinary Department of Medicine, University of Bari "Aldo Moro", 70124 Bari, Italy; massimo.corsalini@uniba.it

* Correspondence: mariafrancesca.cascione@unisalento.it (Mf.C.); valeria.dematteis@unisalento.it (V.D.M.)

\section{check for} updates

Citation: Cascione, M.; De Matteis, V.; Pellegrino, P.; Albanese, G.; De Giorgi,

M.L.; Paladini, F.; Corsalini, M.; Rinaldi, R. Improvement of PMMA Dental Matrix Performance by Addition of Titanium Dioxide Nanoparticles and Clay Nanotubes. Nanomaterials 2021, 11, 2027. https://doi.org/10.3390/ nano11082027

Academic Editors: Jürgen Eckert and May Lei Mei

Received: 25 May 2021

Accepted: 4 August 2021

Published: 9 August 2021

Publisher's Note: MDPI stays neutral with regard to jurisdictional claims in published maps and institutional affiliations.

Copyright: (c) 2021 by the authors. Licensee MDPI, Basel, Switzerland. This article is an open access article distributed under the terms and conditions of the Creative Commons Attribution (CC BY) license (https:/ / creativecommons.org/licenses/by/ $4.0 /)$.
Abstract: Over the last decades, several materials have been proposed for the fabrication of dental and mandibular prosthetic implants. Today, the poly(methyl-methacrylate) (PMMA) resin is the most spread material, due to its ease of processing, low cost, aesthetic properties, low weight, biocompatibility, and biostability in the oral cavity. However, the porous surface (which favors the adhesion of microorganisms) and the weak mechanical properties (which lead to wear or fracture) are the major concerns. The inclusion of engineered nanomaterials in the acrylic matrix could improve the performances of PMMA. In this study, we added two different kind of nanomaterials, namely titanium dioxide nanoparticles ( $\mathrm{TiO}_{2} \mathrm{NPs}$ ) and halloysite clay nanotubes (HNTs) at two concentrations $(1 \%$ and $3 \% w / w)$ in PMMA. Then, we assessed the effect of nanomaterials inclusion by the evaluation of specific physical parameters: Young's modulus, roughness, and wettability. In addition, we investigated the potential beneficial effects regarding the Candida albicans (C. albicans) colonization reduction, the most common yeast responsible of several infections in oral cavity. Our experimental results showed an improvement of PMMA performance, following the addition of $\mathrm{TiO}_{2} \mathrm{NPs}_{\text {and }}$ HNTs, in a dose dependent manner. In particular, the presence of $\mathrm{TiO}_{2} \mathrm{NPs}$ in the methacrylate matrix induced a greater increase in PMMA stiffness respect to HNTs addition. On the other hand, HNTs reduced the rate of $C$. albicans colonization more significantly than $\mathrm{TiO}_{2} \mathrm{NPs}$. The results obtained are of great interest for the improvement of PMMA physico-chemical properties, in view of its possible application in clinical dentistry.

Keywords: $\mathrm{TiO}_{2} \mathrm{NPs}$; HNTs; poly(methyl methacrylate); oral prostheses; mechanical analysis; wettability; Candida albicans

\section{Introduction}

The rehabilitation of masticatory function in edentulous patients, due to trauma, dental diseases or cancer, is one of the aspects of greatest interest in reconstructive medicine and dentistry. The need to improve the quality of oral prostheses and then, the quality of life of patients, has stimulated the research for biocompatible materials (non-toxic, non-irritating, and non-carcinogenic) able to ensure good structural and mechanical performance. In detail, an ideal biomaterial for dental and mandibular prostheses should be chemically stable, mechanically rigid, and non-deformable. In addition, prosthetic material should be resistant to impact and to mechanical stress arising from masticatory forces. Another point to consider is reletad to the aesthetic characheristics; ideally, the color of the material must resemble the color of the oral cavity as closely as possible. For that reason, it should 
be translucent. Finally, the material should be easily workable, repairable, and cleanable, as well as inexpensive.

Although numerous materials have been proposed over the past century [1-3], none of them meet the ideal characteristics described for basic oral prosthetic materials. Today, poly(methylmethacrylate) (PMMA), introduced by "Walter Wright" in 1937, is recognized to be the best with respect to other denture base materials for both complete and partial dentures [4]. PMMA is low cost, low weight, biocompatible, and biostable in oral cavity; in addition, it posses good aesthetic properties.

PMMA is an amorphous polymer formed by the polymerization of the monomer methylmethacrylate; its physical and mechanical properties can be affected by polymerization conditions and fabrication procedures. Several studies have shown that, for dental applications, PMMA requires hot polymerization [5]. In addition, it is also reported some critical issues regarding the processing method; the volatilization of the methylmethacrylate monomers and shrinkage processes that occur during polymerization, resulting in the formation of surface defects such as pores, cracks, and irregularities [6]. These defects, besides to induce deformation resistance of PMMA (i.e., reduction in elastic modulus), and consequently weak mechanical properties, including impact and flexural strengths [7]. At the same time, PMMA became the optimal surface for the growth and proliferation of microrganims [8,9]. Among several species, Candida albicans (C. albicans), an opportunistic yeast, causes the most numerous infections of the oral cavity $[10,11]$. Several studies reported the adhesion behavior of $C$. albicans on surface that significantly increases when the surface roughness is hight [12]; moreover, the superficial irregularities may protect the microorganisms from shear forces associated to the mechanical cleaning processes [13].

In the last decades, several studies have been carried out to improve the physicochemical properties of polymeric materials, including PMMA; in particular, it has been demonstrated that the inclusion of engineered nanomaterials (nanoparticles, nanotubes, nanofibers) in the polymer matrix is capable to modify the material properties [14-16]. These alterations depend on the nanomaterials types, concentration, size, morphology, and surface charge $[17,18]$.

For example, zirconium dioxide NPs $\left(\mathrm{ZrO}_{2} \mathrm{NPs}\right)$ were used in PMMA due to their biocompatibility and high strength, improving the mechanical properties of NPs in a dosedependant manner [19]. However, this effect tended to be reduced when the concentration of NPs increased, provoking agglomeration phenomena that consequently resulted in the worsening of material [20]. Additionally, diamond nanoparticles (DNPs) were added in PMMA for their good thermal conductivity and hardness, but in same cases the aesthetic properties regarding the prosethesis color makes their application difficult for clinical trials [21-23].

Carbon nanotubes (CNTs) were recently applied in PMMA, due to their strong antimicrobial effects and the mechanical properties enhancement [24,25]. However, the breakage of the material due to wear can release CNTs that are know to be toxic, as demonstrated in previously works $[26,27]$.

In this work, using atomic force microscopy (AFM), we evaluated the impact on elastic and surface properties of PMMA after addition by both synthesized titanium dioxide nanoparticles $\left(\mathrm{TiO}_{2} \mathrm{NPs}\right)$ and commercial halloysite clay nanotubes (HNTs) at two different concentrations $(1 \%$ and $3 \% w / w)$.

These two nanomaterials were chosen for their unique physico-chemical properties; in particular, $\mathrm{TiO}_{2} \mathrm{NPs}$ have antibacterial and antimicrobial properties by oxygen radicles production able to destroy the cell wall of some kinds of bacteria inhibiting the biofilm formation [28,29]. Different results can be obtained tuning the NPs size and shape. In addition, the surface properties were responsible of the strong bonds with PMMA chemical groups enhancing the reinforcement effectiveness [30]. HNTs has a hollow/tubular structure constituted by two layers of aluminosilica [31]. CNTs are abundant and cheap natural minerals with biocompatible features [32]. 
Once analyzed the elastic properties, the change of surface roughness and surface contact angle values were estimated following the addition of $\mathrm{TiO}_{2} \mathrm{NPs}$ and HNTs in PMMA, in order to understand a possible contribution to reduce the C. albicans colonization rate and the cell morphology. The results obtained claim the possibility to customize PMMA with different kind of nanomaterials to enhance its efficiency in clinical dental applications.

\section{Materials and Methods}

\subsection{Engineered Nanomaterials: Synthetized $\mathrm{TiO}_{2} \mathrm{NPS}_{\mathrm{S}}$ and Commercial HNTs}

$\mathrm{TiO}_{2} \mathrm{NPs}$ have been synthesized by the sol-gel route [33] with some modifications [34,35]. Titanium (IV) isopropoxide (TTIP, 99,9\%, 377996, Merck, Darmstad, Germany), used as precursor, was dropped in a solution constituting of ethanol and milliQ water in a molar ratio of 5:1:1 under stirring in acidic conditions ( $\mathrm{pH} 3)$. Then, NPs were heated for $5 \mathrm{~h}$ at $30{ }^{\circ} \mathrm{C}$ first, and then at $430{ }^{\circ} \mathrm{C}$ for $3 \mathrm{~h}$ in order to obtain a white nano powder.

The commercial HNTs (n. 685445, Merck, Darmstadt, Germany) were kindly donated by Prof. Yuri Lvov (Louisiana Tech University, Ruston, LA, USA).

\subsection{Morphological and Compositional Characterization of $\mathrm{TiO}_{2} \mathrm{NPS}_{\mathrm{S}}$ and HNTs}

Scanning electron microscopy (SEM) and energy-dispersive X-ray spectroscopy (EDS) measurements were performed using a JEOL JSM-6480LV microscope (Jeol Inc, Peabody, MA, USA), with a magnification of up to $10,000 \times$. The SEM images have been acquired at an accelerating voltage of $5 \mathrm{kV}$ (in order to better distinguish the surface details), whereas EDX measurements need higher accelerating voltages in order to ionize the atoms in the sample and induce $\mathrm{X}$-ray emission.

The samples were prepared dissolving $5 \mathrm{mg}$ of $\mathrm{TiO}_{2} \mathrm{NPs}_{\text {or }} \mathrm{HNTs}$ in $10 \mathrm{~mL}$ of milliQ water. Then, after one sonication cycle $(10 \mathrm{~min}, 59 \mathrm{MHz})$, the nanomaterials were deposited on monocrystalline silicon wafer by drop casting.

\subsection{Fabrication of PMMA Based Samples}

The PMMA based specimens were obtained by mixing, in a glass container, $5 \mathrm{~g}$ of Paladon 65 powder (Kultzer, Germany) and $3 \mathrm{~mL}$ of Paladon 65 liquid (Kultzer, Germany); they were mixed manually using a steel spatula until the mixture reached a semi-liquid consistency. After 3 min of rest, necessary for the resin to acquire a semi-plastic consistency, the mixture was poured into hard silicone moulds (80 shore hardness) and then transferred into a Pentatlon 205 machine (Effegi Brega, Sarmoto, Italy); here the polymerization of the samples was achieved in $30 \mathrm{~min}$, setting the pressure at $5 \mathrm{~atm}$ and the temperature at $100{ }^{\circ} \mathrm{C}$.

The cured PMMA specimens were treated then roughened, finished and polished. More specifically, the surfaces were polished using first a tungsten carbide multi-blade and then silicone rubbers of decreasing grain size (from $40-100 \mu \mathrm{m}$ ), mounted on a rotating instrument (SILFRADENT S.R.L, S. Sofia, Italy) (50,000 rpm). Subsequently, the surface was polished using a cotton-wool brush mounted on a laboratory cleaner (SILFRADENT S.R.L, S. Sofia Italy) with water and pumice powder, and finally rubbed with a dry cotton-wool brush polishing liquid for resins (Dentaurum, Bologna, Italy).

In the case of PMMA implemented with engineered nanomaterials, $\mathrm{TiO}_{2} \mathrm{NPs}(1 \%$ and $3 \% w / w)$ or HNTs $(1 \%$ and $3 \% w / w)$ were added to Paladon 65 powder before adding the Paladon 65 liquid component.

\subsection{Color Analysis}

The PMMA discs were photographed, using a reflex digital camera (Canon EOS 100D, Tokyo, Japan) mounted on a homemade setup to ensure that the objective-sample distance was always the same and under the same lighting conditions.

For each samples, the values of the RGB color components were obtained using the 'color histogram' tool of the ImageJ 1.47v software (National Institutes of Health, Bethesda, MD, USA). 


\subsection{Wettability Characterization}

Wettability measurements were performed according to the sessile drop method. The experimental setup used is equipped with high-speed $\mathrm{b} / \mathrm{w}$ motion analysis (Redlake Imaging MotionScope (DEL imaging, Woodsville, NH, USA)), linear positioner (Holmark, Kalamassery, Kerala, India) with integrated tilting stage, led backlight diffuser (Edmund, Reno, NV, USA) with intensity control, and microliter droplets dispenser module (Hamilton, York, UK). The measurements, carried out at room temperature $\mathrm{T}=(20.5 \pm 0.5){ }^{\circ} \mathrm{C}$ and relative humidity $\mathrm{RH}=(55 \pm 5) \%$, were performed by depositing $\approx 3 \mu \mathrm{L}$ of a drop of distilled water on the sample; making sure that the deposition of the drops occurred slowly, in order to prevent them from falling. Droplet deposition was recorded by frame grabber system from transient phase to steady-state configuration in which the static contact angle was measured.

For each of the sample (PMMA, PMMA + $\mathrm{TiO}_{2} \mathrm{NPs} 1 \%$, $\mathrm{PMMA}+\mathrm{TiO}_{2} \mathrm{NPs} 3 \%$, PMMA + HNTs $1 \%$ and PMMA + HNTs 3\%) 10 drops were used.

Recorded images were processed by using two different programs, Java plug-in of ImageJ $1.47 \mathrm{v}$ software (National Institutes of Health, Bethesda, MD, USA) and Ossila Contact Angle (Ossila, Sheffield, UK) [36]. This approach allowed to improve the static contact angle measurements, overcoming the limits related both to the asymmetry of droplets and to the sensitivity of image analysis techniques, including image contrast and left and right three-phase point identification, to reconstruct the contour based on the sharpness of grayscale pixels [37].

\subsection{Atomic Force Microscopy (AFM) Analysis}

High resolution AFM NTEGRA (NT-MDT Spectrum Instruments, Moskow, Russia) was employed to investigate morphology and roughness of samples. These measurements were performed using CSG01 probe (NT-MDT Spectrum Instruments, Moskow, Russia), These measurements were performed using CSG01 probe (NT-MDT Spectrum Instruments, Moskow, Russia). This tip have a tetrahedral shape, having a typical tip curvature radius smaller than $10 \mathrm{~nm}$, and a tip cone angle less than $20^{\circ}$. The tip is mounted on a rectangular single crystal silicon cantilever with a thickness of $1.25 \mu \mathrm{m}$, a typical spring constant of about $0.03 \mathrm{~N} / \mathrm{m}$ and resonant frequency is $15.06 \mathrm{kHz}$. The topographic acquisitions were taken in contact error mode, over areas of $50 \mu \mathrm{m} \times 50 \mu \mathrm{m}$ with a resolution of 1024 points $\times 1024$ points, with setpoint and gain parameters set to $1.1 \mathrm{nA}$ and 0.34 , respectively.

Further acquisitions were made on areas of $5 \mu \mathrm{m} \times 5 \mu \mathrm{m}$; these images were analyzed by Image Analysis P9 (NT-MDT Co.) software (NT-MDT Spectrum Instruments, Moskow, Russia) to accurately estimate roughness parameter, expressed as $\mathrm{Rq}$ and calculated as root mean square of height fluctuations respect to mean height value obtained by all data images. Prior to perform Rq quantification, each topographical image was treated with a second order plane fit and with a second order flattening in order to cancel every bow and tridimensionality effects.

In order to quantify the sample elasticity, force indentation curves were obtained using DPC20 probes (NT-MDT Spectrum Instruments, Moskow, Russia) that consists in high sensitivity V-shaped cantilever having tip cone angle less than $22^{\circ}$, curvature radius equal to $100 \mathrm{~nm}$. The nominal resonant frequency and elastic spring constant indicated by the manufacturer amount to $420 \mathrm{kHz}$ and $65 \mathrm{~N} / \mathrm{m}$, respectively. Therefore, prior to perform the force-spectroscopy measurements, the spring constant of DPC20 cantilevers was accurately estimated via the thermal noise method [38]. All measurements were performed in ambient conditions (room temperature of about $25^{\circ} \mathrm{C}$ and relative humidity around $55 \%$ ). The approach data portion of indentation curves were fitted using the Sneddon model and the Young's Modulus $(E)$ value was obtained as best fit parameter. For each sample, the $E$ was calculated as mean value on 50 indentation curves. 


\subsection{C. albicans Colonization Analyses}

C. albicans yeast working solution were obtained growing yeast cells in Sabouraud dextrose broth (SDB) (ThermoFisher, Waltham, MA, USA) for $18 \mathrm{~h}$ at $37^{\circ} \mathrm{C}$ with shaking at $150 \mathrm{rpm}$. Prior to perform the yeast adhesion experiments, the $C$. albicans cells were harvested by centrifugation at $3000 \mathrm{rpm}$ for $10 \mathrm{~min}$; finally, cell density was adjusted to $1 \times 10^{7}$ cells $/ \mathrm{mL}$ in SDB.

$1 \mathrm{~mL}$ of working solution were seeded on different PMMA-based samples (PMMA, $\mathrm{PMMA}+\mathrm{TiO}_{2} \mathrm{NPs} 1 \%$, PMMA + $\mathrm{TiO}_{2} \mathrm{NPs} 3 \%$, PMMA + HNTs $1 \%$, PMMA + HNTs $3 \%$ ), previously placed into 24-well tissue culture plate (Corning, St. Louis, MO, USA), in order to quantify the yeast colonization rate after incubation at $37^{\circ} \mathrm{C}$ for $24 \mathrm{~h}$ and $48 \mathrm{~h}$. At these time points, after gently washing with sterile PBS to remove non-adherent cells, adherent cells were fixed by immersion in methanol $(50 \% v / v)$ for $2 \mathrm{~min}$. After drying, samples were metallized with gold (approximately $10 \mathrm{~nm}$ thickness) before examination by scanning electron microscopy (JEOL USA, Inc, Peabody, MA, USA). The acquisitions obtained were analyzed with the open-source software ImageJ $1.47 \mathrm{v}$ software (National Institutes of Health, Bethesda, MD, USA), in order to quantify the percentage of colonized area.

In order to evaluate the morphological alterations of $C$. albicans yeast cells on different PMMA-based substrate, the atomic force microscopy surface characterizations were carried out in semicontact mode. The measurements were carried out using a single crystal siliconantimony doped NGS 01 probe (NT-MDT Spectrum Instruments, Moskow, Russia), having a typical curvature radius of $10 \mathrm{~nm}$, nominal resonant frequency of $150 \mathrm{kHz}$, and nominal elastic spring constant equal to $5.1 \mathrm{~N} / \mathrm{m}$.

The acquisitions were achieved, for both time points, over scan area equal to 50 over areas of $15 \mu \mathrm{m} \times 15 \mu \mathrm{m}$ with a resolution of 768 points $\times 768$ points;

In addition, further acquisitions were made on areas of $5 \mu \mathrm{m} \times 5 \mu \mathrm{m}$ with resolution of 512 points $\times 512$ points, in order to better appreciate the morphological changes in C. albicans yeast cells, after $24 \mathrm{~h}$ and $48 \mathrm{~h}$. The parameters setpoint, gain and scan set parameters used were fixed to $4.5 \mathrm{nA}, 0.3$, and $0.5 \mathrm{~Hz}$, respectively.

\subsection{Statistical Analysis}

Results were expressed as mean value and associated standard deviation. Differences between different mean values were considered statistically significant respect to control (PMMA substrate) performing a Student's $t$-test with a $p$-value $<0.05\left(<0.05^{*},<0.01 * *\right.$ and $\left.<0.005^{* * *}\right)$.

\section{Results and Discussion}

Nowadays, PMMA is the common material used for oral prosthesis, despite there are some concerns regarding its suitability, due to the susceptibility to the fractures under the continuous action of chewing forces.

In this work, we evaluated the change in PMMA properties following its implementation with two different types of engineered nanomaterial: $\mathrm{TiO}_{2} \mathrm{NPs}$ and HNTs.

We first characterized the nanomaterials using SEM to acquire information about their morphology (Figure 1).

$\mathrm{TiO}_{2} \mathrm{NPs}$ exhibited an irregular quasi-spherical shape (Figure 1a) with an average diameter of (50 \pm 1$) \mathrm{nm}$ (Figure 1c); HNTs showed the standard nanotubes morphology (Figure $1 \mathrm{~b})$ with an average dimensions of $(1.4 \pm 0.2) \mu \mathrm{m}$ in length and $(0.08 \pm 0.03) \mu \mathrm{m}$ in height (Figure 1d), confirming the size value indicated by the manufacturer. Size statistical analysis of the NPs mean size and size distribution were performed by using the fitting analysis available on OriginPro software (OriginLab version 8, OriginLab Corporation, Northampton, MA, USA).

As showed in Figure $1 \mathrm{c}, \mathrm{d}$, the analyses corroborated the size distribution of the nanomaterials observed in SEM images, for $\mathrm{TiO}_{2} \mathrm{NPs}$ and HNTs respectively. 
a)

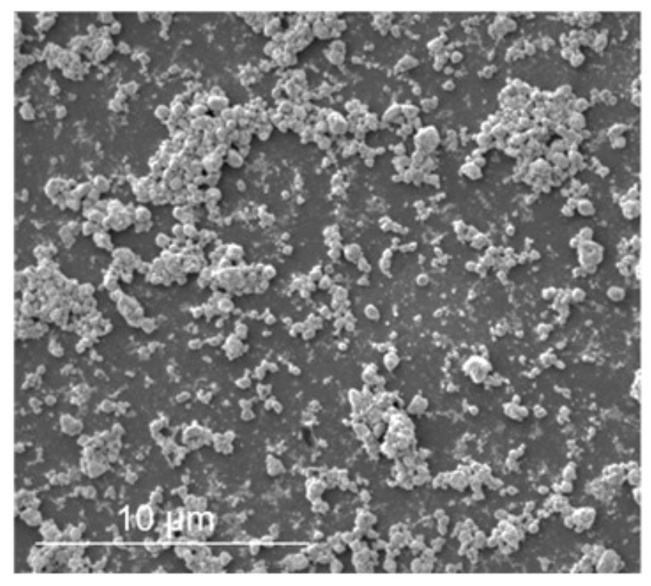

c)

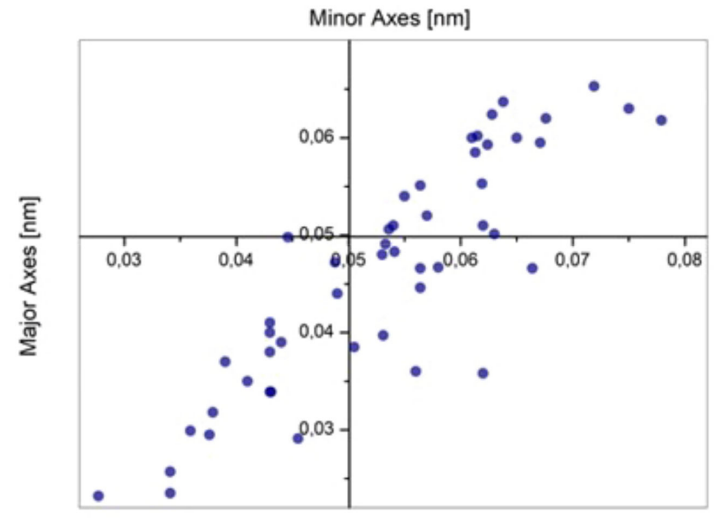

e)

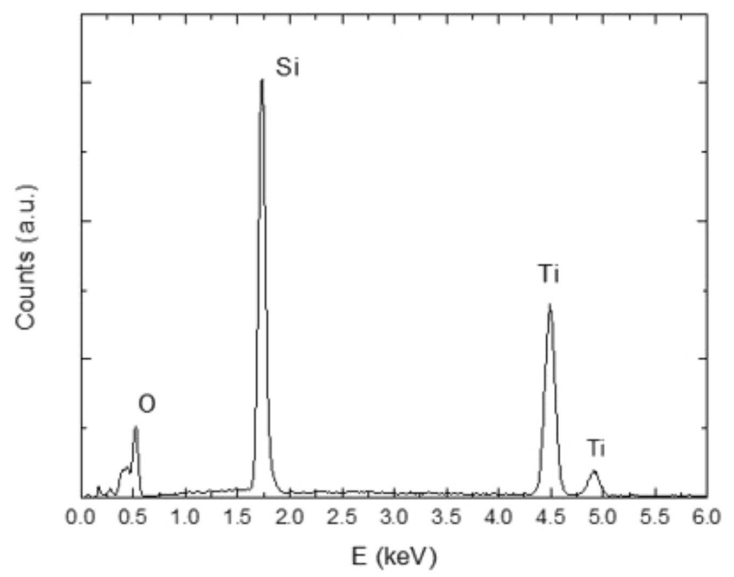

b)

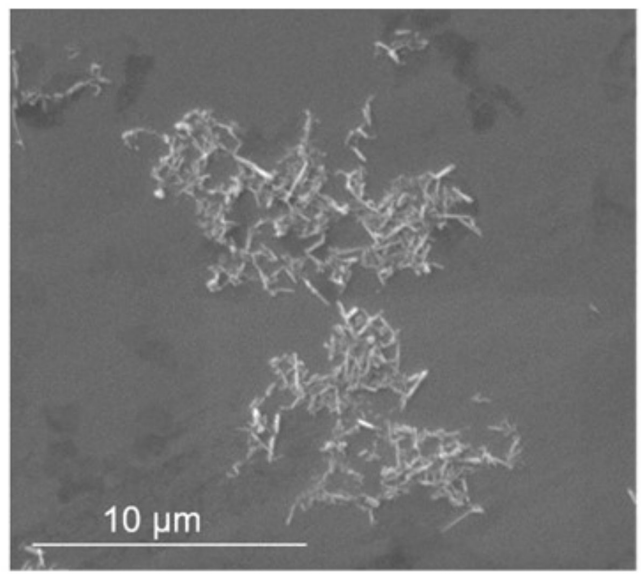

d)

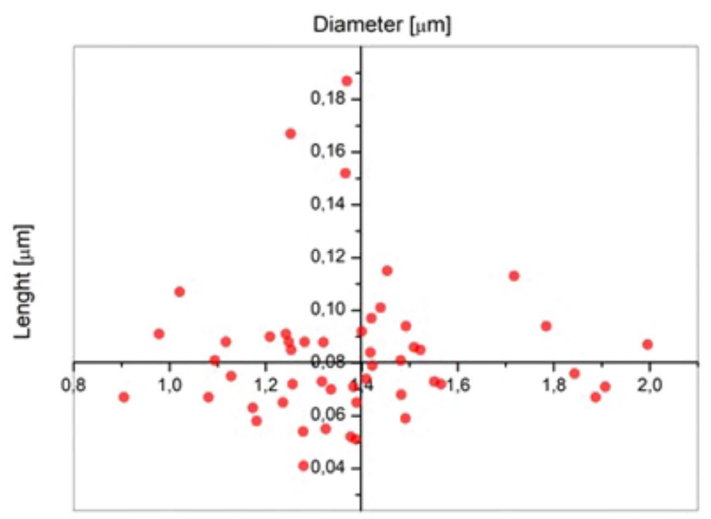

f)

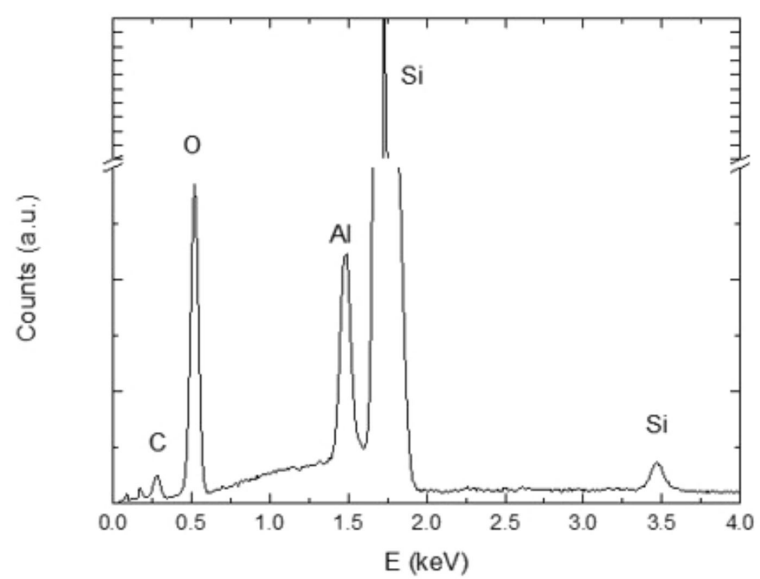

Figure 1. Representative SEM acquisitions of $\mathrm{TiO}_{2} \mathrm{NPs}(\mathbf{a})$ and $\mathrm{HNTs}(\mathbf{b})$ on monocrystalline silicon wafer at the accelerating voltage of $5 \mathrm{kV}$. Size distribution of $\mathrm{TiO}_{2} \mathrm{NPs}(\mathbf{c})$, in terms of major and minor axes length, and HNTs size distribution (d), in terms of diameter and lenght dimensions. EDS characterization (accelerating voltage $20 \mathrm{kV}$ ) of $\mathrm{TiO}_{2} \mathrm{NPs}_{(\mathbf{e})}$ and $\mathrm{HNTs}(\mathbf{f})$. 
The EDS microanalysis conducted on $\mathrm{TiO}_{2} \mathrm{NPs}$ displayed the presence of titanium (Ti) and oxygen $(\mathrm{O})$ in $\mathrm{TiO}_{2} \mathrm{NPs}$ and the absence of other chemical species (Figure 1e); the silicon (Si) peak was referred to the substrate (silicon wafer). Similarly, the EDS spectrum acquired for the HNTs samples showed peaks related to aluminium (Al), silicon and oxygen atoms (Figure 1f), in accordance with nanotubes composition. The peaks assigned to silicon in Figure $1 \mathrm{f}$ are due to the concurrent contributions of the nanotubes and the substrates.

After characterization by SEM analysis, the two types of nanomaterials were added to the methyl-methacrylate resin at two different concentrations during sample preparation: $1 \% w / w$ and $3 \% w / w$. After PMMA polymerisation, the nanomaterials were trapped in the methyl-methacrylate matrix. The first visible effect of their presence was the change in the color of the material (Figure 2).

a)

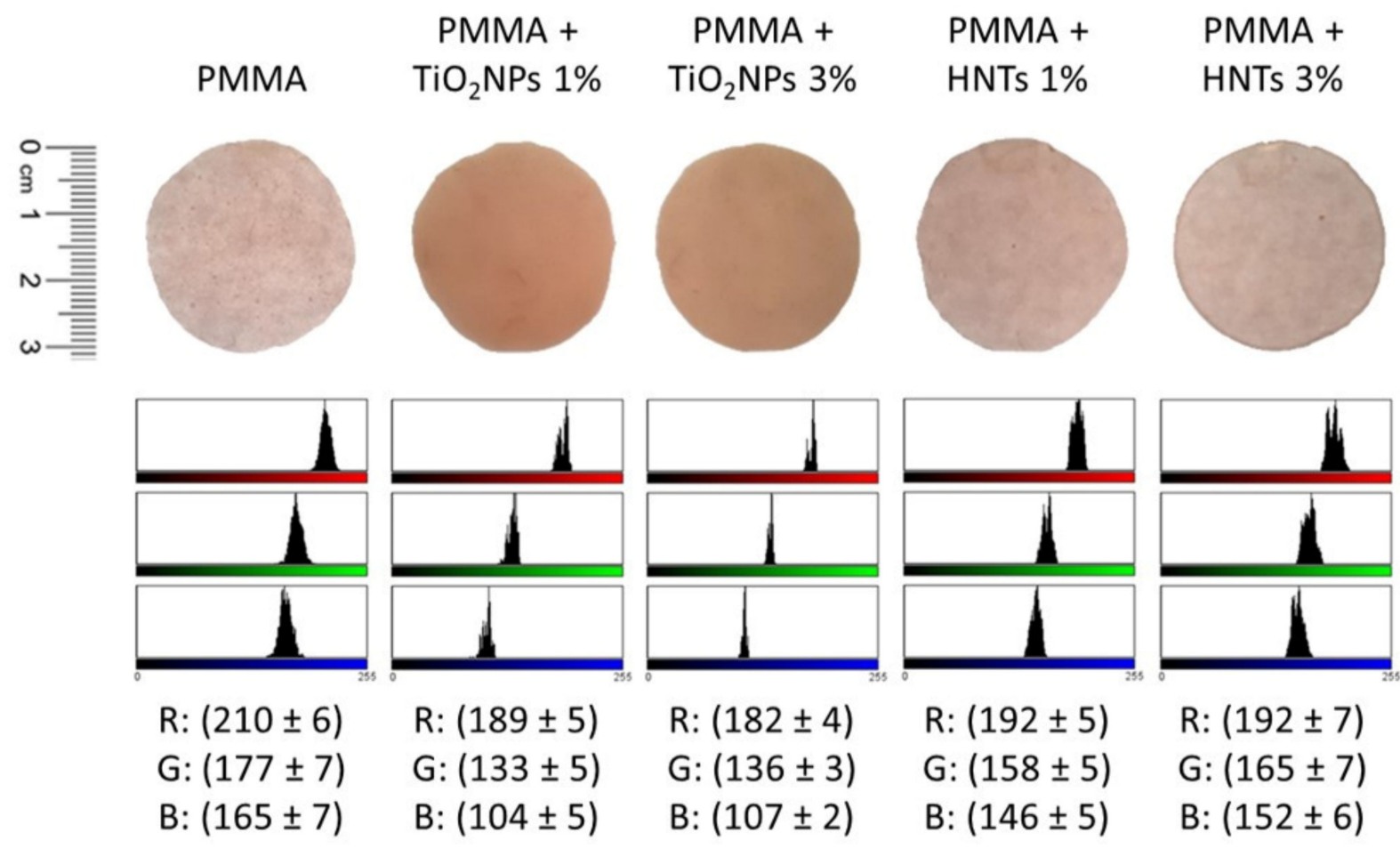

Figure 2. PMMA-based material samples images acquired with camera (a) and the corresponding RGB color analysis (b).

The addition of HNTs did not alter the color of the PMMA, which remained pink and translucent like control, whereas the addition of $\mathrm{TiO}_{2} \mathrm{NPs}$ made the resin opaque (Figure 2a). These evidences were confirmed by RGB analysis, from which was evident how the value of red, green and blu channels after $\mathrm{TiO}_{2} \mathrm{NPs}$ addition $(1 \%$ and $3 \%$ ) changed respect to undoped PMMA (Figure $2 b$ ). Contrary, the HNTs did not produce significative changes in the three RGB channels (Figure 2b). The color change is a key aspect for aesthetic purposes because PMMA-based materials are destinated to be used in clinical practice. Subsequently, the impact of the nanomaterials addition in the methacrylate resin was evaluated in terms of elasticity and roughness using AFM.

The results obtained by Young's modulus estimation (Figure 3) clearly demonstrated that the inclusion of $\mathrm{HNTs}$ or $\mathrm{TiO}_{2} \mathrm{NPs}$ triggered a stiffness alteration in the PMMA matrix, as suggested by the different slope of the linear approach portion in the force-distance curves (Figure 3a). 
a)

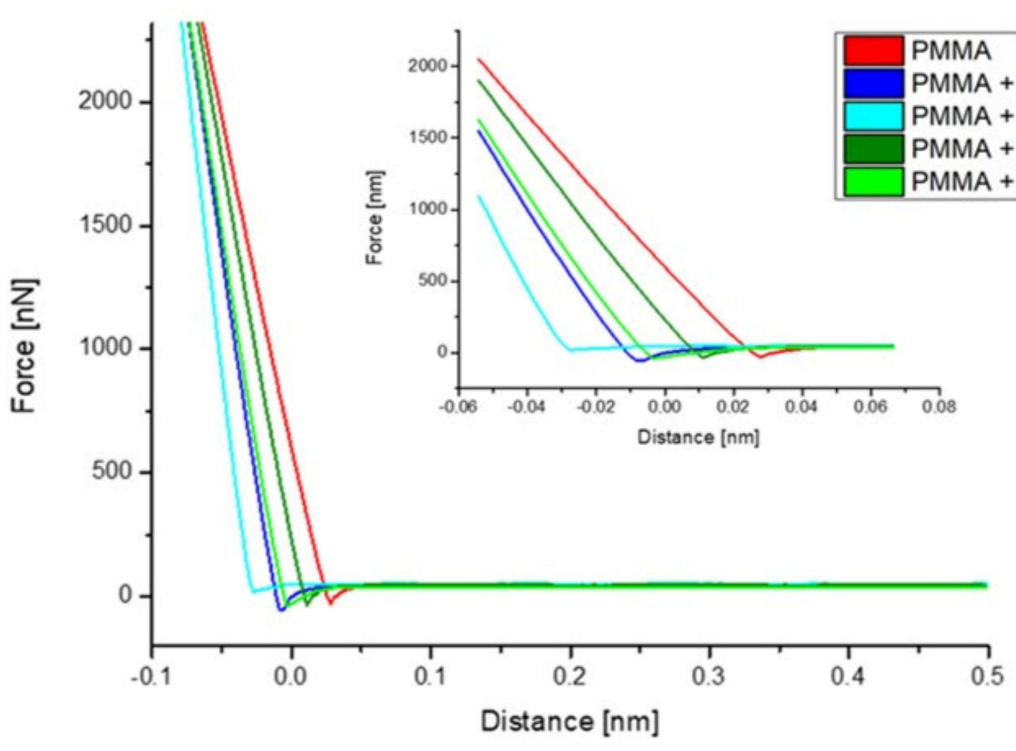

b)

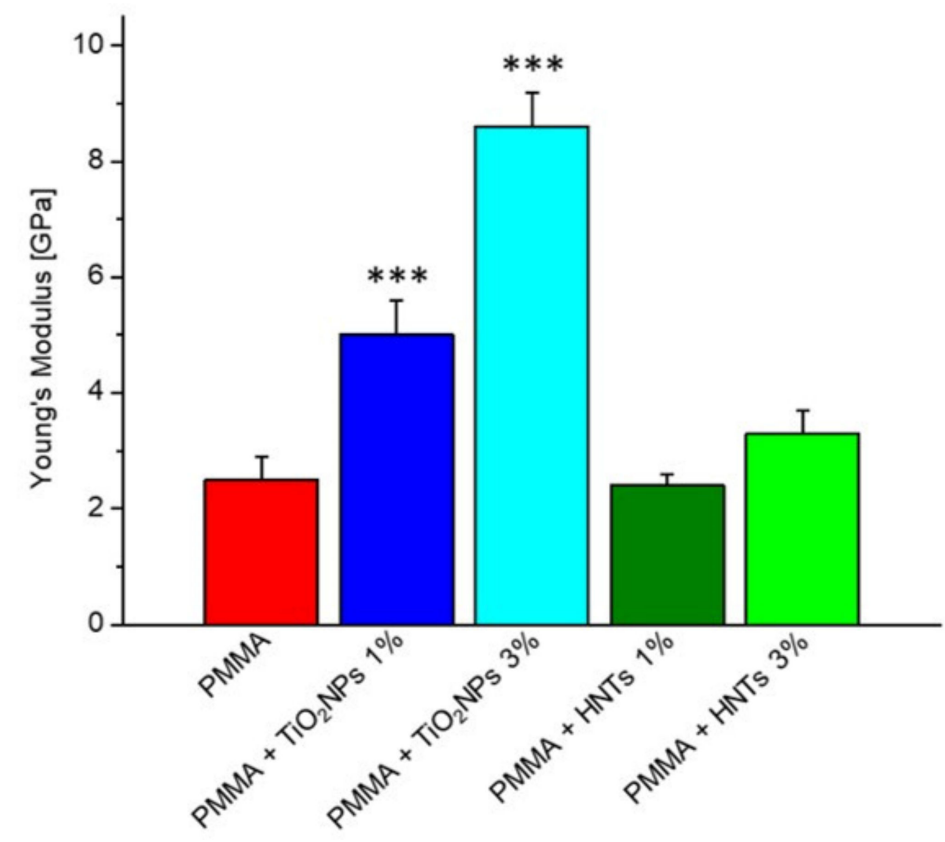

Figure 3. (a) Representative force-distance curves (only approach data portion) recorded on different PMMA-based materials. In the histogram (b) the mean value and its standard deviation of Young's Modulus, evaluated for control (PMMA), $\mathrm{PMMA}+\mathrm{TiO}_{2} \mathrm{NPs} 1 \%, \mathrm{PMMA}+\mathrm{TiO}_{2} \mathrm{NPs}_{3} \%$, $\mathrm{PMMA}+\mathrm{HNTs} 1 \%$, and PMMA+ HNTs $3 \%$ were represented. Reported results were considered statistically significant respect to control (PMMA) for $p$-value $<0.005^{* * *}$.

In details, the Young's modulus estimated for the samples PMMA, PMMA + $\mathrm{TiO}_{2} \mathrm{NPs}$ 1\%, PMMA $+\mathrm{TiO}_{2} \mathrm{NPs} 3 \%, \mathrm{PMMA}+\mathrm{HNTs} 1 \%, \mathrm{PMMA}+\mathrm{HNTs} 3 \%$ showed how the presence of nanomaterials in the resin increased the PMMA stiffness (Figure 3b), which was equal to $(2.5 \pm 0.4) \mathrm{GPa}$ in the control sample, increasing considerably in the samples in which $\mathrm{TiO}_{2} \mathrm{NPs}$ was added, becoming equal to $(5.0 \pm 0.6) \mathrm{GPa}$ in $\mathrm{PMMA}+\mathrm{TiO}_{2} \mathrm{NPs} 1 \%$ and (8.6 \pm 0.6$) \mathrm{GPa}$ in PMMA $+\mathrm{TiO}_{2} \mathrm{NPs} 3 \%$.

The Young's Modulus value in the PMMA + HNTs 1\% sample did not change respect to the control, remaining equal to $(2.4 \pm 0.2) \mathrm{GPa}$, while a slight increase was recorded for PMMA + HNTs $3 \%$, becoming equal to $(3.3 \pm 0.4) \mathrm{GPa}$. 
The explanation of the best performance of $\mathrm{TiO}_{2}$ NPs in PMMA matrix could be due by a chemical and physical interactions with the carboxylic groups (-COOR) of PMMA in different manner. For example, the binding can occur by a bidentate coordination between $\mathrm{Ti}^{4+}$ cation and the two oxygen atoms of -COOR. Alternatively, the bond can take place

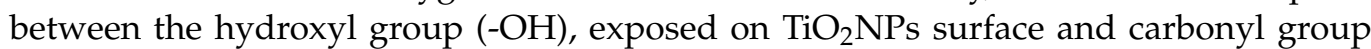
$(-\mathrm{C}=\mathrm{O})$ of PMMA [39]. Moreover, the addition of $\mathrm{TiO}_{2} \mathrm{NPs}_{\mathrm{s}}$ is particularly suitable to fill the interpolymeric space [40].

The HNTs filled in the matrix, and the potential agglomeration could decrease their degree of anisotropy due to the increase to the weak van der Walls interactions with the PMMA matrix [41].

The best values regarding the mechanical rigidity were recorded when $\mathrm{TiO}_{2} \mathrm{NPs}$ were added in PMMA (Figure 3b). In the case of HNTs, the increase of Young's modulus value become significant using the concentration of $3 \% w / w$. Contrary, the effect on the mechanical improvement of PMMA implemented with $\mathrm{TiO}_{2} \mathrm{NPs}$ was considerable even at the lowest concentration tested in this work $(1 \% w / w)$.

High-resolution atomic force scans performed in contact error mode, permit to simultaneously estimate the height local changes (heigh channel) and to appreciate more details about the features present on the sample surface (DFL channel). The topographic acquisitions revealed that the PMMA surface became smoother when the engineered nanomaterials were included in the matrix (Figure 4).

a)

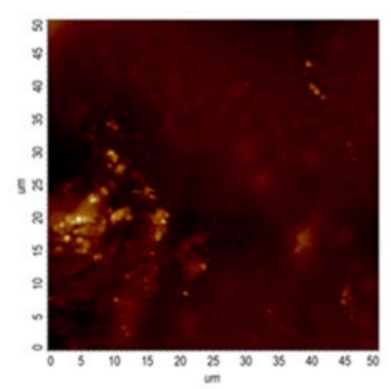

c)

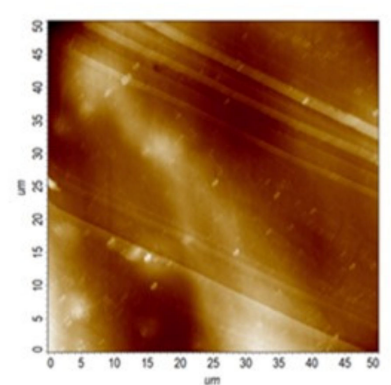

e)

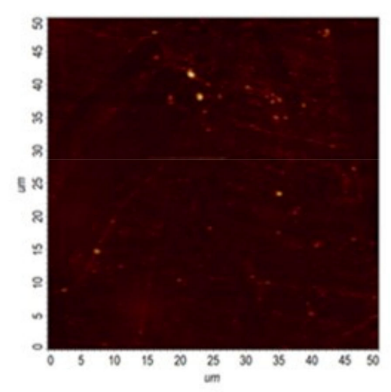

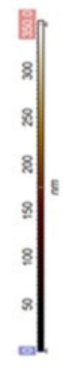
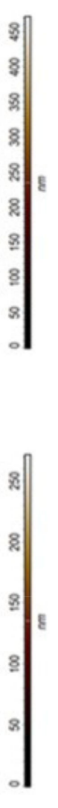

b)
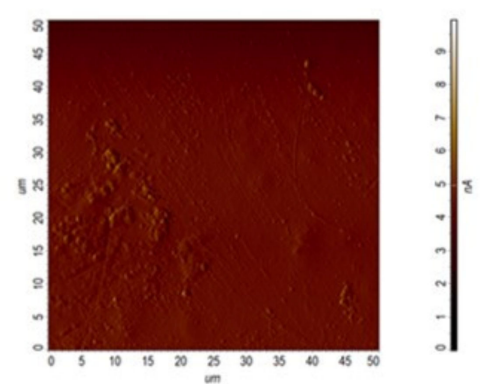

d)

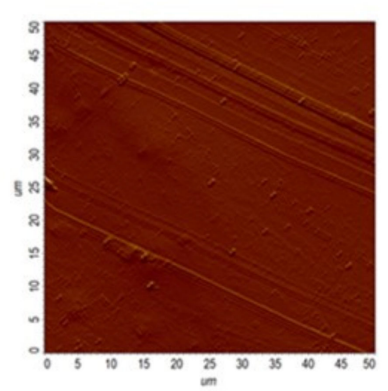

f)

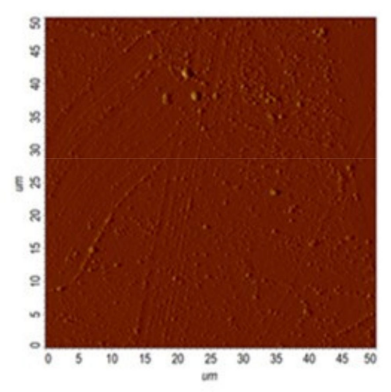

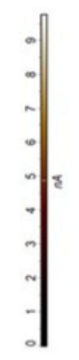

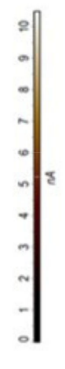

Figure 4. Cont. 
g)

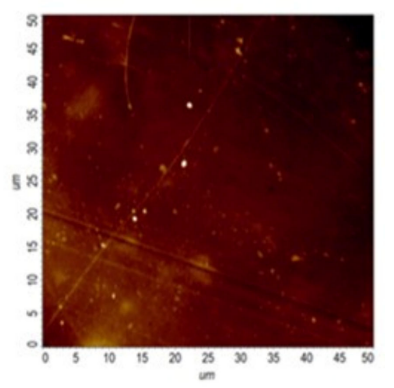

i)

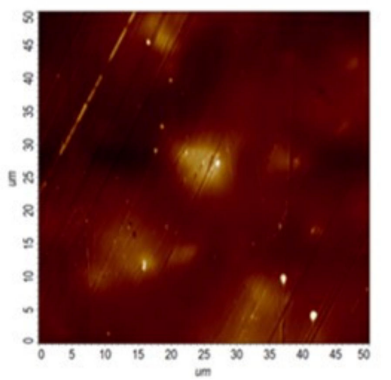

h)
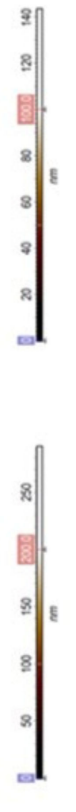

l)
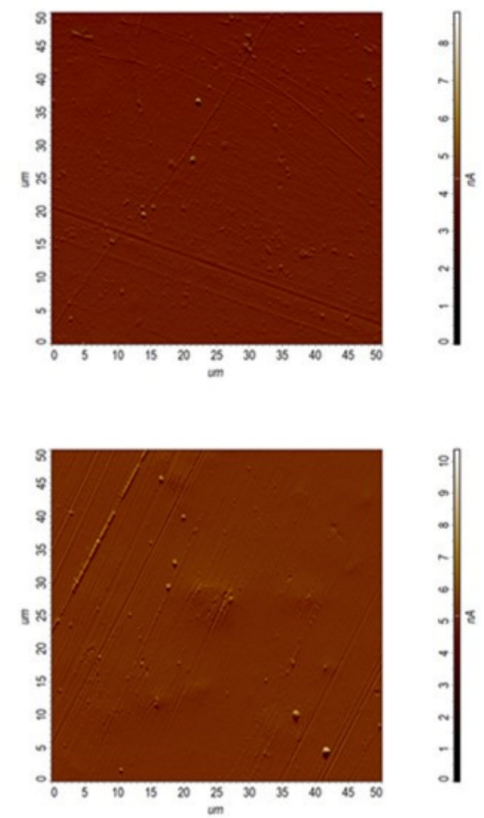

Figure 4. Representative topographical acquisitions obtained by atomic force microscopy in the height and deflection channel, obtained for PMMA (a,b), PMMA + $\mathrm{TiO}_{2} \mathrm{NPs} 1 \%(\mathbf{c}, \mathbf{d})$, PMMA + $\mathrm{TiO}_{2}$ NPs $3 \%(\mathbf{e}, \mathbf{f})$, PMMA+ HNTs 1\% (g,h), PMMA+ HNTs 3\% (i,ll) substrates.

The analysis of the surface properties of the PMMA-based materials revealed a drastic reduction of the roughness parameter for both nanomaterials added to the methacrylate matrix, depending on their concentration (Figure 5).

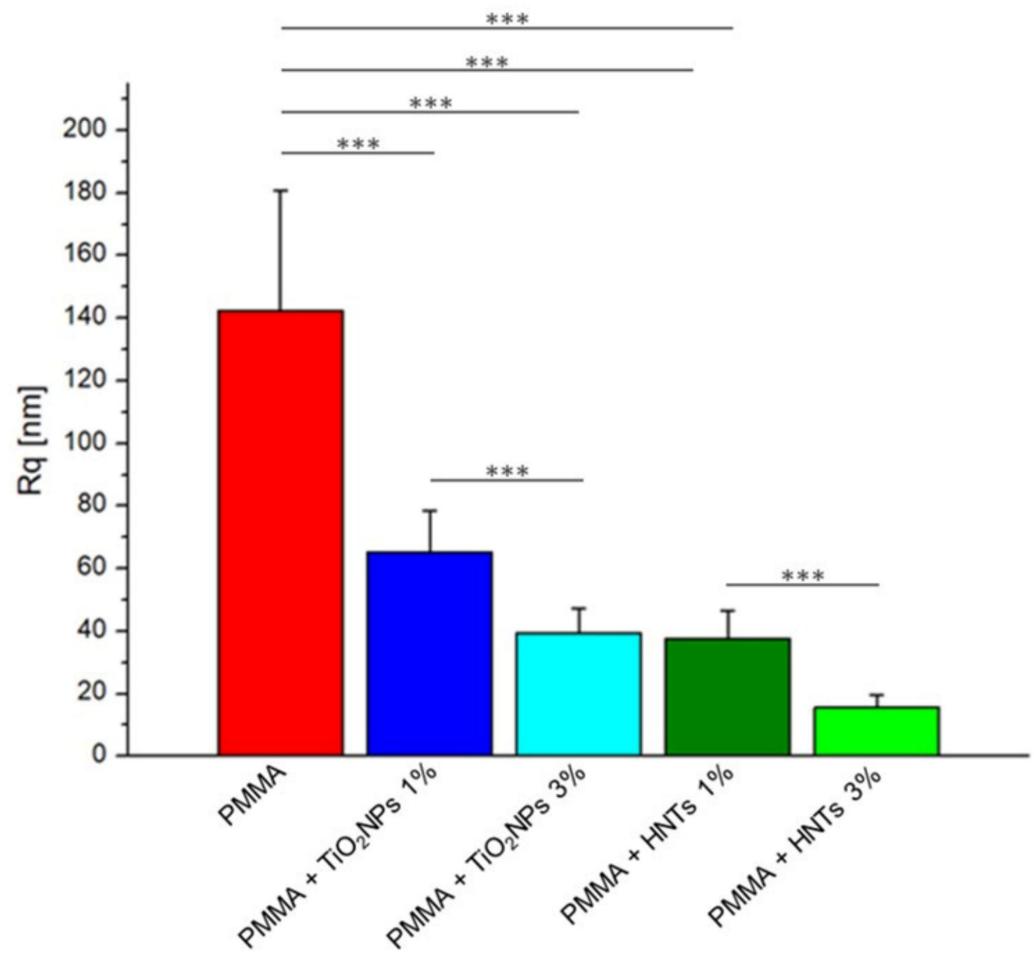

Figure 5. Roughness values (Rq) expressed as mean value and standard deviation on PMMA-based substrates. Obtained Rq value were considered statistically significant respect to control (PMMA) for $p$-value $<0.005^{* * *}$. 
As shown in the histogram, the roughness value of the PMMA sample, equal to $(142 \pm 38) \mathrm{nm}$ was reduced by $54 \%$ when $\mathrm{TiO}_{2} \mathrm{NPs} 1 \% w / w$ was added; such value decreased up to $72 \%$ when the concentration of $\mathrm{TiO}_{2} \mathrm{NPs}$ was $3 \% w / w$. Better results were recorded using PMMA + HNTs 1\% and 3\% samples, in which the Rq value decreased of $73 \%$ and $89 \%$ respect to the control sample.

In general, to test the wettability, the contact angle is measured. This parameter is described as the angle at the interface where water, air and solid converge. High contactangle values of certain surfaces display the surface's tendency to repel water; on the contrary, low values referred to the water tendency to spread on the surface [42]. By the contact angle measurements, we verified the wettable nature of PMMA after nanomaterials addition at $1 \%$ and $3 \% w / w$ (Figure 6 ).

\section{PMMA}

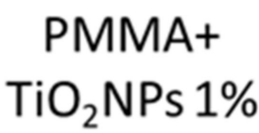

PMMA+ HNTs $1 \%$
PMMA+ HNTs $3 \%$

\section{Contact angle $\left({ }^{\circ}\right)$}

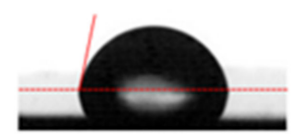

$87 \pm 3$

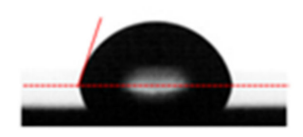

$80 \pm 3$

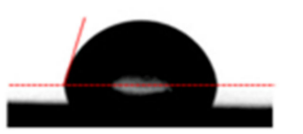

$80 \pm 2$

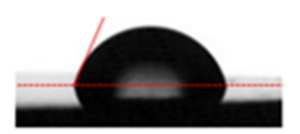

$76 \pm 3$

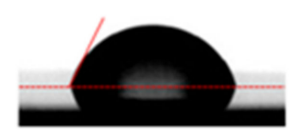

$72 \pm 2$

Figure 6. Water contact angle measurements. Representative images of water droplets on different PMMA-based materials and the correspondent contact angle values, obtained as mean on different 10 experiments $\pm \mathrm{sd}$.

More exactly, the value of the water contact angle recorded for PMMA sample (control) was equal to $(87 \pm 3)^{\circ}$, and it decreased when $\mathrm{TiO}_{2} \mathrm{NPs}$ or HNTs were added. More specifically, the values of this parameter become equal to $(76 \pm 3)^{\circ}$ and $(72 \pm 5)^{\circ}$ in PMMA+ HNTs $1 \%$ and $3 \%$ samples, respectively. Our results were in close agreement with the results reported by Wei and colleagues [43], although the nanotubes concentrations used were different from those used in our work.

The implementation of PMMA with $\mathrm{TiO}_{2} \mathrm{NPs}$ less significantly reduced the contact angle value, which was equal to $80^{\circ}$ regardless of the concentration of NPs $(1 \%$ and $3 \%$ $w / w)$ added to the methacrylate matrix.

Thus, we found that the hydrophilicity increased in PMMA + HNTs than in $\mathrm{PMMA}+\mathrm{TiO}_{2} \mathrm{NPs}$ samples, whereas the roughness value was smaller.

It has been largely demonstrated how the $\mathrm{Rq}$ and wettability parameters affect both the material biocompatibility and the possible pathogen or yeast colonization.

As reported in clinical literature, most oral infections developed by patients wearing dental or mandibular prostheses are due to the uncontrolled proliferation of the yeast C. albicans $[44,45]$. This yeast is able to reduce the lifetime of the prosthetic implant and in addition to this, it strongly worsens the health of the oral cavity negatively impacting on the patient's quality of life.

SEM acquisitions (Figure 7) suggested that the rate of colonization by C. albicans yeast decreased on PMMA substrates implemented with $\mathrm{TiO}_{2} \mathrm{NPs}$ and this reduction become pronounced in PMMA + HNTs samples.

Following the SEM images analysis byusing ImageJ software, the percentage of colonized area after $24 \mathrm{~h}$ on the PMMA $+\mathrm{TiO}_{2} \mathrm{NPs} 1 \%$ and $3 \%$ samples was reduced by $16 \%$ and $19 \%$, respectively, compared to the control sample. After $48 \mathrm{~h}$, the percentage of colonisation respect to undoped PMMA further decreased to $22 \%$ and $26 \%$ on the $\mathrm{PMMA}+\mathrm{TiO}_{2} \mathrm{NPs} 1 \%$ and $3 \%$ substrates, respectively (Figure 8 ). 
a)

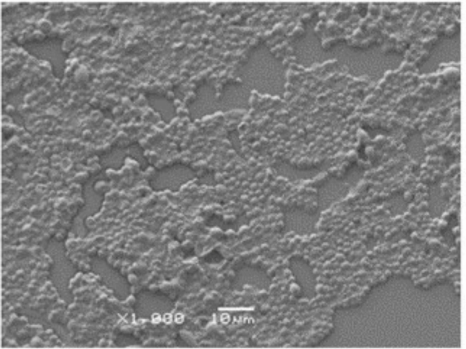

c)

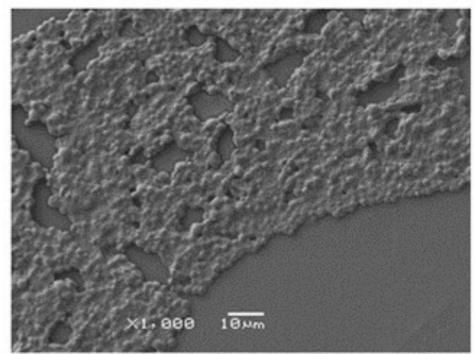

e)

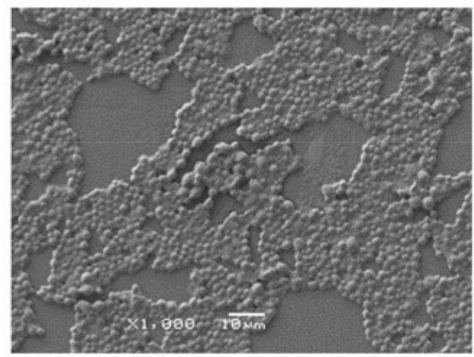

g)

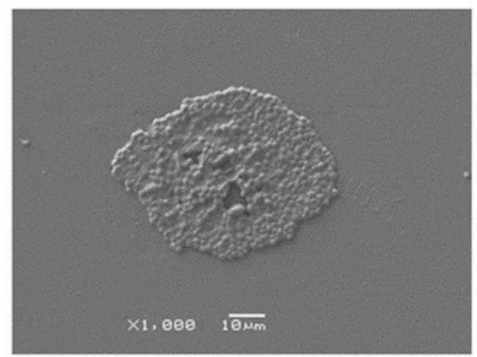

i)

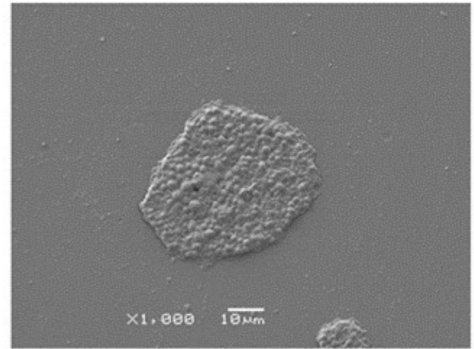

b)

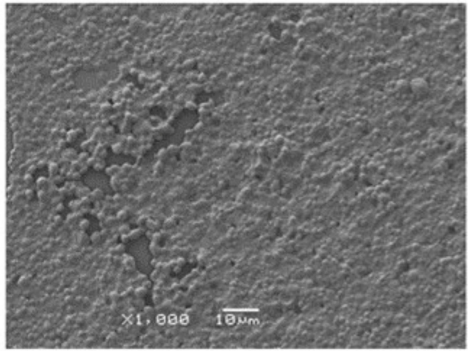

d)

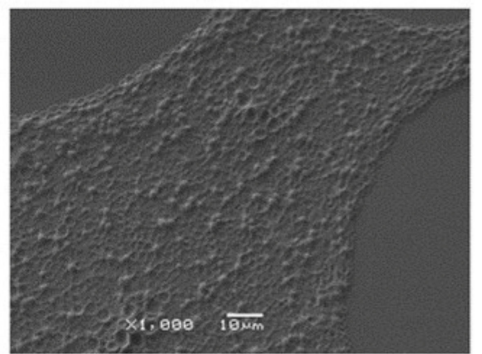

f)

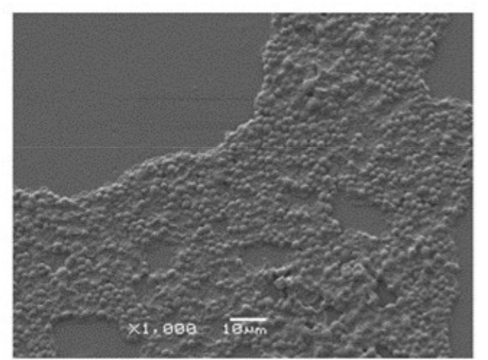

h)

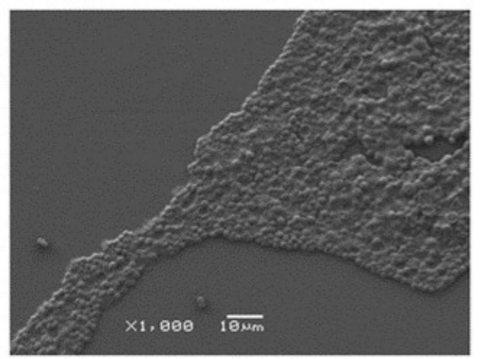

l)

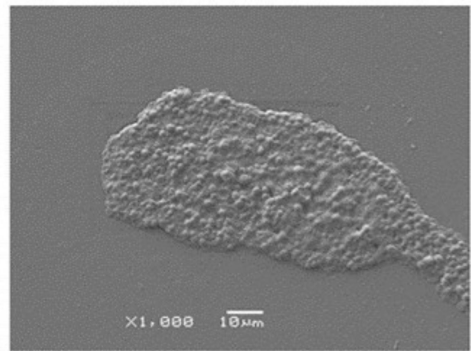

Figure 7. Representative SEM images at $1000 \times$ magnifications of $C$. albicans presence on different PMMA-based substrates: PMMA (a,b), PMMA + $\mathrm{TiO}_{2} \mathrm{NPs} 1 \%(\mathbf{c}, \mathbf{d}), \mathrm{PMMA}+\mathrm{TiO}_{2} \mathrm{NPs} 3 \%(\mathbf{e}, \mathbf{f})$, PMMA+ HNTs $1 \%(\mathbf{g}, \mathbf{h})$, PMMA+ HNTs $3 \%(\mathbf{i}, \mathbf{l})$ substrates at different time points $24 \mathrm{~h}(\mathbf{a}, \mathbf{c}, \mathbf{e}, \mathbf{g}, \mathbf{i})$ and 48 h (b,d,f,h, $\mathbf{l})$. 


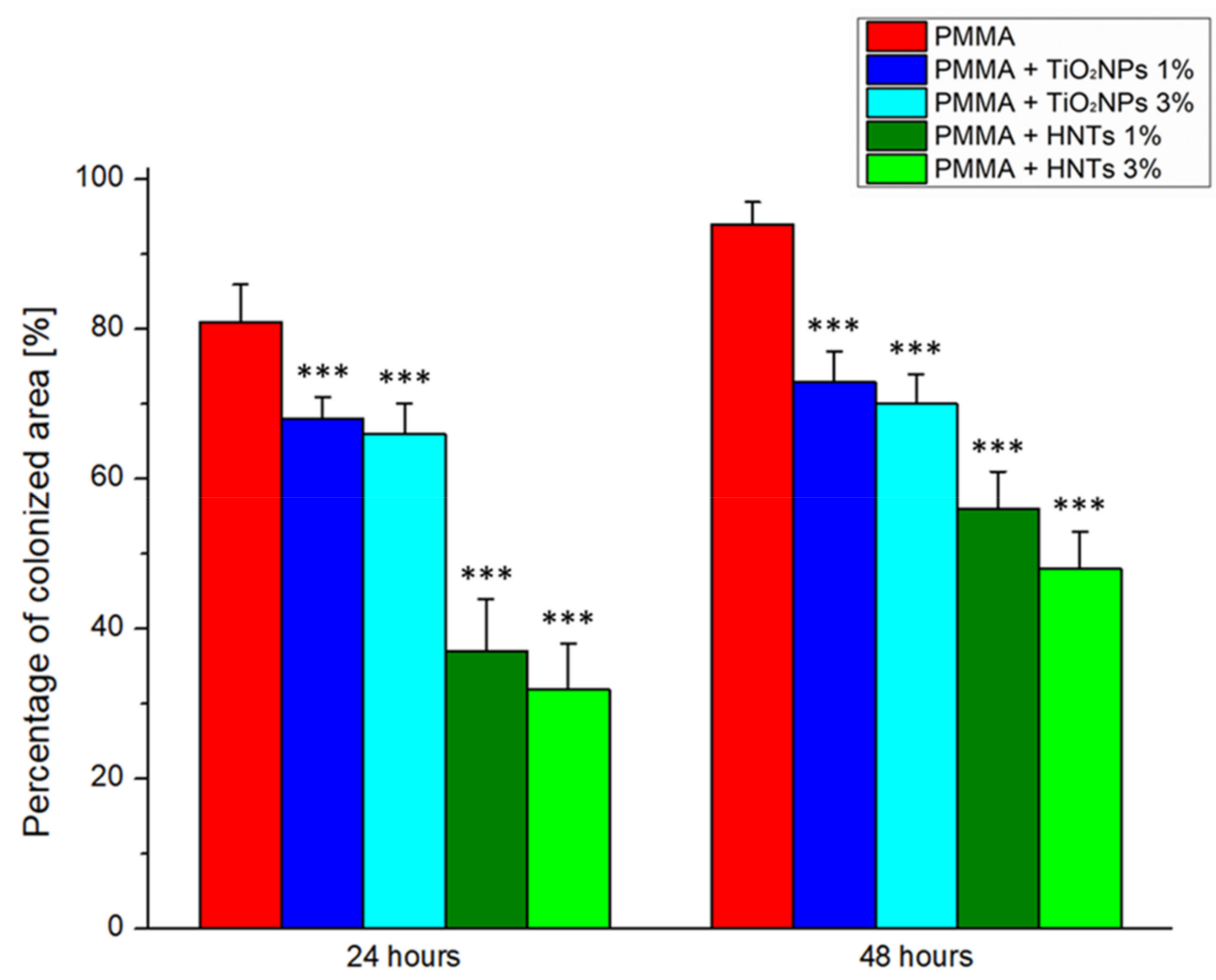

Figure 8. Histograms reported the Colonization assay measurements of C. albicans on different PMMA-based substrates. The colonized area was expressed as a percentage rate of the C. albicans covered area respect to entire acquired surface at two time points ( $24 \mathrm{~h}$ and $48 \mathrm{~h}$ ). Reported results were calculated as average \pm SD on three different area on each sample, and the values were considered statistically significant respect to control (PMMA at correspondent time point) for $p$-value $<0.005 * * *$.

The addition of HNTs to methacrylate resin inhibited the Candida colonization in a stronger manner than the undoped PMMA.

After $24 \mathrm{~h}$, the percentage of colonized area on the PMMA + HNTs 1\% and 3\% substrates was reduced by $54 \%$ and $60 \%$ compared to the control. At $48 \mathrm{~h}$, this reduction become equal to $40 \%$ for PMMA + HNTs $1 \%$ and $49 \%$ for PMMA + HNTs 3\%. These results, obtained on three different areas on each sample, were corroborated by morphological observations of $C$. albicans cells, obtained by AFM acquisitions (Figure 9).

The implementation of PMMA with $\mathrm{TiO}_{2} \mathrm{NPs}(1 \%$ and $3 \%)$ did not show any significant alteration, indeed the morphology of fungus appeared similar to untreated sample, in both time points. Contrary, the addition of HNTs both at $1 \%$ and $3 \% w / w$ produced visible alterations of cells morphology: C. albicans appeared collapsed and deformed with irregular shape. These effects become more pronounced after $48 \mathrm{~h}$ (Figure 9).

In summary, we concluded that the inclusion of engineered nanomaterials can improve the performance of PMMA for its use in buccal prosthetic implants. The addition of $\mathrm{TiO}_{2} \mathrm{NPs}$ increased the mechanical stiffness of the methacrylate resin, providing an improved wear and fracture resistance, and decreased the PMMA roughness. However, this additive dulls the methacrylate resin, making it less aesthetically pleasing. In contrast, the PMMA matrices implemented with HNTs preserved the translucency of the methacrylate resin but weakly improves its mechanical properties. The major advantage of this additivation is related to the strongly reduction in the $C$. albicans ability to adhere and proliferate, thank to the lowest surface roughness and more hydrophilic behavior [46,47]. In addition, the low toxic profile of these kind of NPs on living cells, make sure that they are the best choice to customize PMMA, compared to other types of nanomaterials [48-51]. 
a)

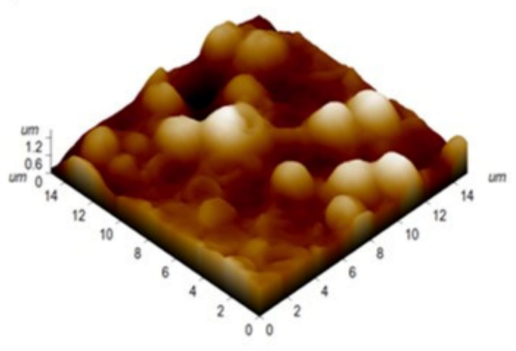

c)

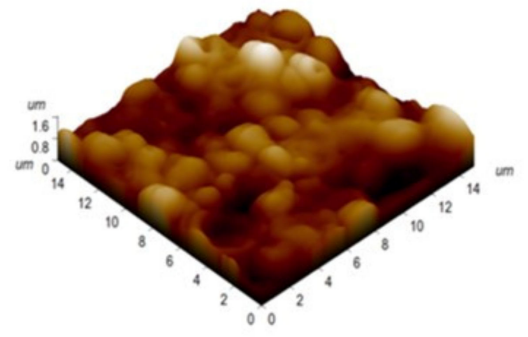

e)

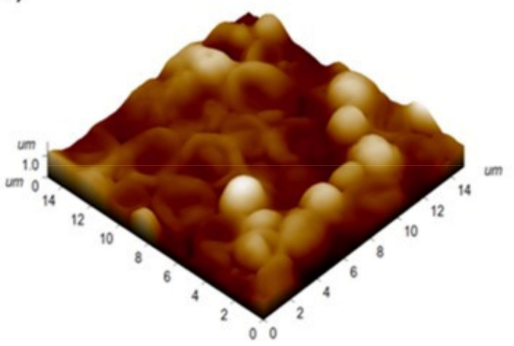

g)

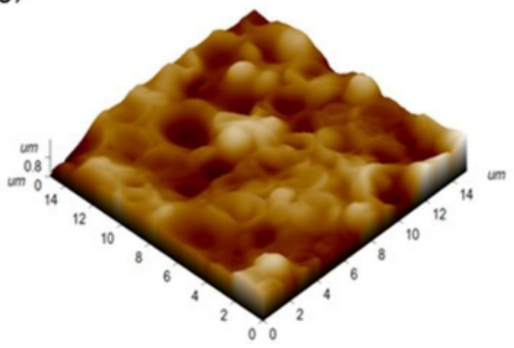

i)

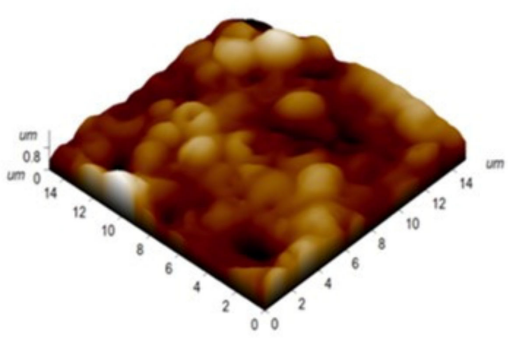

b)

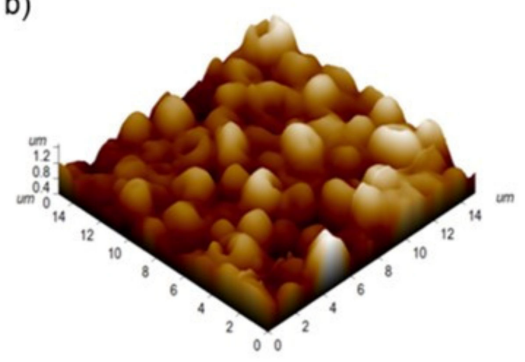

d)

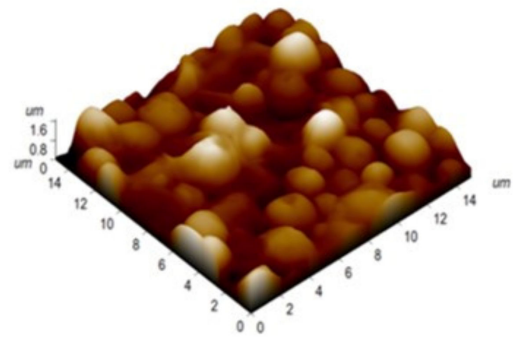

f)

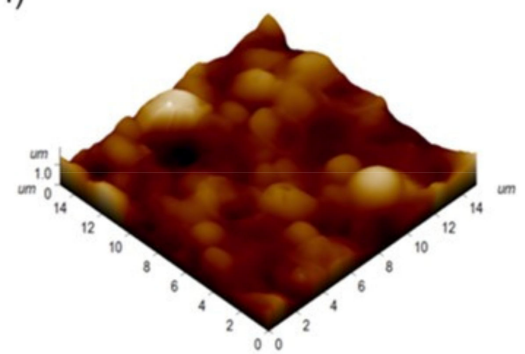

h)

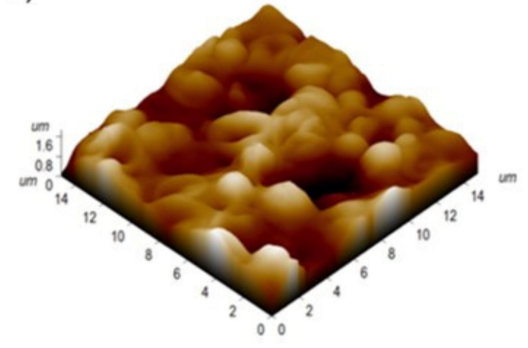

I)

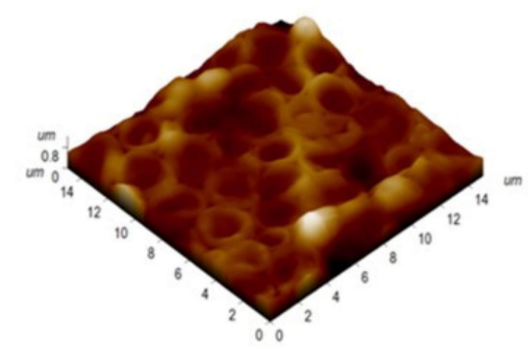

Figure 9. Three dimensional AFM topographical acquisitions, performed on PMMA (a,b), $\mathrm{PMMA}+\mathrm{TiO}_{2} \mathrm{NPs} 1 \%$ (c,d), PMMA + $\mathrm{TiO}_{2} \mathrm{NPs} 3 \%$ (e,f), PMMA+ HNTs 1\% (g,h), PMMA+ HNTs $3 \%(\mathbf{i}, \mathbf{l})$ substrates after $24 \mathrm{~h}(\mathbf{a}, \mathbf{c}, \mathbf{e}, \mathbf{g}, \mathbf{i})$ and $48 \mathrm{~h}(\mathbf{b}, \mathbf{d}, \mathbf{f}, \mathbf{h}, \mathbf{l})$ of $C$. albicans colonization. 


\section{Conclusions}

In recent years, the scientific research has focused great attention to improve the performance of materials used for prosthetic applications. In particular, there are aneed to develop strategies to inhibit $C$. albicans adhesion and proliferation, which represent the main cause of deterioration in oral prosthetic implants.

Our work outline interesting perspectives in the reconstructive dentistry field, suggesting as the implementation of nanomaterials can be a useful strategy to improve PMMA properties. In the light of the reported results, we encourage the HNTs addition especially to prevent the C. albicans infections.

In the future, clinical trials could be performed in order to evaluate the impact of natural oral biofilm and $\mathrm{pH}$ condition on HNTs-doped PMMA properties.

Author Contributions: Mf.C. (Mariafrancesca Cascione) and V.D.M. conceptualize the research work and conceived the experimental activities. V.D.M. synthetized $\mathrm{TiO}_{2}$ NPs. G.A. fabricated the PMMA-based samples and prepared the samples for microbiological tests. P.P., M.L.D.G., F.P. performed AFM, SEM, contact angle measurements, respectively. Mf.C. (Mariafrancesca Cascione) performed data analysis, explained the experimental results, and wrote the paper. V.D.M. and R.R. edited and drafted the work. R.R. and Mf.C. (Massimo Corsalini) revised and given final approval for publication. All authors have read and agreed to the published version of the manuscript.

Funding: This research received no external funding.

Institutional Review Board Statement: Not applicable.

Informed Consent Statement: Not applicable.

Data Availability Statement: Not applicable.

Acknowledgments: Mf.C. (Mariafrancesca Cascione) and V.D.M. kindly acknowledge Programma Operativo Nazionale (PON) Ricerca e Innovazione 2014-2020 Asse I “Capitale Umano", Azione I.2, Avviso "A.I.M: Attraction and International Mobility" (CUP F88D1800060001) (CUP F88D1800070001) for funding their fellowship and research activities. All authors kindly acknowledge Yuri Lvov (Louisiana Tech University, USA) for providing the commercial HNTs (no. 685445, Merck, Germany) used in this work.

Conflicts of Interest: The authors declare no conflict of interest.

\section{References}

1. Cramer, N.B.; Stansbury, J.W.; Bowman, C. Recent Advances and Developments in Composite Dental Restorative Materials. J. Dent. Res. 2011, 90, 402-416. [CrossRef] [PubMed]

2. Alla, R.K.; Swamy, K.N.; Vyas, R.; Konakanchi, A. Conventional and Contemporary Polymers for the Fabrication of Denture Prosthesis: Part I-Overview, Composition and Properties. Int. J. Appl. Dent. Sci. 2015, 1, 82-89.

3. Papadiochou, S.; Pissiotis, A.L. Marginal Adaptation and CAD-CAM Technology: A Systematic Review of Restorative Material and Fabrication Techniques. J. Prosthet. Dent. 2018, 119, 545-551. [CrossRef]

4. Ladha, K.; Shah, D. An In-Vitro Evaluation of the Flexural Strength of Heat-Polymerized Poly (Methyl Methacrylate) Denture Resin Reinforced with Fibers. J. Indian Prosthodont. Soc. 2011, 11, 215. [CrossRef] [PubMed]

5. Zafar, M.S. Prosthodontic Applications of Polymethyl Methacrylate (PMMA): An Update. Polymers 2020, 12, 2299. [CrossRef]

6. Kasina, S.P.; Ajaz, T.; Attili, S.; Surapaneni, H.; Cherukuri, M.; Srinath, H.P. To evaluate and compare the porosities in the acrylic mandibular denture bases processed by two different polymerization techniques, using two different brands of commercially available denture base resins-An in vitro study. J. Int. Oral Health 2014, 6, 72-77.

7. Sakaguchi, R.; Power, J. Craig's Restorative Dental Materials, 13th ed.; Elsevier Health Sciences: Amsterdam, The Netherlands, 2012; ISBN 9780323081085.

8. Ayaz, E.A.; Durkan, R.; Koroglu, A.; Bagis, B. Comparative Effect of Different Polymerization Techniques on Residual Monomer and Hardness Properties of PMMA-Based Denture Resins. J. Appl. Biomater. Funct. Mater. 2014, 12, 228-233. [CrossRef]

9. Arenas-Arrocena, M.C.; Argueta-Figueroa, L.; García-Contreras, R.; Martínez-Arenas, O.; Camacho-Flores, B.; del RodriguezTorres, M.P.; de la Fuente-Hernández, J.; Acosta-Torres, L.S. New Trends for the Processing of Poly(Methyl Methacrylate) Biomaterial for Dental Prosthodontics. In Acrylic Polymers in Healthcare; InTech: London, UK, 2017.

10. Moura, J.S.; Jose Da Silva, W.; Pereira, T.; Del, A.A.; Cury, B.; Cunha, R.; Rodrigues Garcia, M. Influence of Acrylic Resin Polymerization Methods and Saliva on the Adherence of Four Candida Species. J. Prosthet. Dent. 2006, 96, 205-211. [CrossRef] 
11. Mehendale, A. 47. Adherence of Candida Albicans on Polyamides in Comparison with Conventional Acrylic Surfaces-A Short Study. J. Indian Prosthodont. Soc. 2018, 18, 71. [CrossRef]

12. Pereira-Cenci, T.; Cury, A.A.D.B.; Cenci, M.S.; Rodrigues-Garcia, R.C.M. In Vitro Candida Colonization on Acrylic Resins and Denture Liners: Influence of Surface Free Energy, Roughness, Saliva, and Adhering Bacteria. Int. J. Prosthodont. 2007, 20, 308-310. [PubMed]

13. Al-Bakri, I.; Harty, D.; Al-Omari, W.; Swain, M.; Chrzanowski, W.; Ellakwa, A. Surface Characteristics and Microbial Adherence Ability of Modified Polymethylmethacrylate by Fluoridated Glass Fillers. Aust. Dent. J. 2014, 59, 482-489. [CrossRef]

14. Aeran, H.; Kumar, V.; Uniyal, S.; Tanwer, P. Nanodentistry: Is just a Fiction or Future. J. Oral Biol. Craniofac. Res. 2015, 5, $207-211$. [CrossRef] [PubMed]

15. Asar, N.V.; Albayrak, H.; Korkmaz, T.; Turkyilmaz, I. Influence of Various Metal Oxides on Mechanical and Physical Properties of Heat-Cured Polymethyl Methacrylate Denture Base Resins. J. Adv. Prosthodont. 2013, 5, 241-247. [CrossRef] [PubMed]

16. Ali Sabri, B.; Satgunam, M.; Abreeza, N.; Abed, A. A Review on Enhancements of PMMA Denture Base Material with Different Nano-Fillers. Cogent Eng. 2021, 8, 1875968. [CrossRef]

17. Wang, W.; Liao, S.; Zhu, Y.; Liu, M.; Zhao, Q.; Fu, Y. Recent Applications of Nanomaterials in Prosthodontics. J. Nanomater. 2015, 2015, 1-11. [CrossRef]

18. De Matteis, V.; Cascione, M.; Toma, C.C.; Albanese, G.; de Giorgi, M.L.; Corsalini, M.; Rinaldi, R. Silver Nanoparticles Addition in Poly(Methyl Methacrylate) Dental Matrix: Topographic and Antimycotic Studies. Int. J. Mol. Sci. 2019, $20,4691$. [CrossRef] [PubMed]

19. Gad, M.M.; Al-Thobity, A.M.; Rahoma, A.; Abualsaud, R.; Al-Harbi, F.A.; Akhtar, S. Reinforcement of PMMA Denture Base Material with a Mixture of $\mathrm{ZrO}_{2}$ Nanoparticles and Glass Fibers. Int. J. Dent. 2019, 2019, 1-11. [CrossRef]

20. Gad, M.M.; Fouda, S.M.; Al-Harbi, F.A.; Näpänkangas, R.; Raustia, A. PMMA Denture Base Material Enhancement: A Review of Fiber, Filler, and Nanofiller Addition. Int. J. Nanomed. 2017, 12, 3801-3802. [CrossRef] [PubMed]

21. Mangal, U.; Kim, J.-Y.; Seo, J.-Y.; Kwon, J.-S.; Choi, S.-H. Novel Poly(Methyl Methacrylate) Containing Nanodiamond to Improve the Mechanical Properties and Fungal Resistance. Materials 2019, 12, 3438. [CrossRef]

22. Karbushev, V.V.; Konstantinov, I.I.; Parsamyan, I.L.; Kulichikhin, V.G.; Popov, V.A.; George, T.F. Preparation of PolymerNanodiamond Composites with Improved Properties. Adv. Mater. Res. 2008, 59, 275-278. [CrossRef]

23. Gad, M.M.; Abualsaud, R.; Al-Thobity, A.M.; Baba, N.Z.; Al-Harbi, F.A. Influence of Addition of Different Nanoparticles on the Surface Properties of Poly(Methylmethacrylate) Denture Base Material. J. Prosthodont. 2020, 29, 422-428. [CrossRef]

24. Turagam, N.; Prasad Mudrakola, D. Effect of Micro-Additions of Carbon Nanotubes to Polymethylmethacrylate on Reduction in Polymerization Shrinkage. J. Prosthodont. 2013, 22, 105-111. [CrossRef]

25. Tiraferri, A.; Vecitis, C.D.; Elimelech, M. Covalent Binding of Single-Walled Carbon Nanotubes to Polyamide Membranes for Antimicrobial Surface Properties. ACS Appl. Mater. Interfaces 2011, 3, 2869-2877. [CrossRef]

26. Saleemi, M.A.; Hosseini Fouladi, M.; Yong, P.V.C.; Chinna, K.; Palanisamy, N.K.; Wong, E.H. Toxicity of Carbon Nanotubes: Molecular Mechanisms, Signaling Cascades, and Remedies in Biomedical Applications. Chem. Res. Toxicol. 2021, 34, 24-46. [CrossRef]

27. Francis, A.P.; Devasena, T. Toxicity of Carbon Nanotubes: A Review. Toxicol. Ind. Health 2018, 34, 200-210. [CrossRef] [PubMed]

28. Ghahremani, L.; Shirkavand, S.; Akbari, F.; Sabzikari, N. Tensile Strength and Impact Strength of Color Modified Acrylic Resin Reinforced with Titanium Dioxide Nanoparticles. J. Clin. Exp. Dent. 2017, 9, e661-e665. [CrossRef]

29. Youssef, F.; Farghaly, U.; Abd El-Baky, R.M.; Waly, N. Comparative Study of Antibacterial Effects of Titanium Dioxide Nanoparticles Alone and in Combination with Antibiotics on MDR Pseudomonas aeruginosa Strains. Int. J. Nanomed. 2020, 15, 3393-3404. [CrossRef] [PubMed]

30. Chatterjee, A. Properties Improvement of PMMA Using Nano TiO 2. J. Appl. Polym. Sci. 2010, 118, 2890-2897. [CrossRef]

31. Guimarães, L.; Enyashin, A.N.; Seifert, G.; Duarte, H.A. Structural, Electronic, and Mechanical Properties of Single-Walled Halloysite Nanotube Models. J. Phys. Chem. C 2010, 114, 11358-11363. [CrossRef]

32. Leporatti, S.; Cascione, M.; de Matteis, V.; Rinaldi, R. Design of Nano-Clays for Drug Delivery and Bio-Imaging: Can Toxicity Be an Issue? Nanomedicine 2020, 15, 2429-2432. [CrossRef]

33. Leena, M.; Srinivasan, S. Synthesis and Ultrasonic Investigations of Titanium Oxide Nanofluids. J. Mol. Liq. 2015, 206, 103-109. [CrossRef]

34. Cascione, M.; de Matteis, V.; Mandriota, G.; Leporatti, S.; Rinaldi, R. Acute Cytotoxic Effects on Morphology and Mechanical Behavior in MCF-7 Induced by TiO2NPs Exposure. Int. J. Mol. Sci. 2019, 20, 3594. [CrossRef] [PubMed]

35. De Matteis, V.; Cascione, M.; Toma, C.C.; Pellegrino, P.; Rizzello, L.; Rinaldi, R. Tailoring Cell Morphomechanical Perturbations Through Metal Oxide Nanoparticles. Nanoscale Res. Lett. 2019, 14, 109. [CrossRef] [PubMed]

36. Stalder, A.F.; Melchior, T.; Müller, M.; Sage, D.; Blu, T.; Unser, M. Low-Bond Axisymmetric Drop Shape Analysis for Surface Tension and Contact Angle Measurements of Sessile Drops. Colloids Surf. A Physicochem. Eng. Asp. 2010, 364, 72-81. [CrossRef]

37. Chini, S.F.; Amirfazli, A. A Method for Measuring Contact Angle of Asymmetric and Symmetric Drops. Colloids Surf. A Physicochem. Eng. Asp. 2011, 388, 29-37. [CrossRef]

38. Butt, H.-J.; Cappella, B.; Kappl, M. Force Measurements with the Atomic Force Microscope: Technique, Interpretation and Applications. Surf. Sci. Rep. 2005, 59, 1-152. [CrossRef]

39. Cierech, M.; Szerszeń, M.; Wojnarowicz, J.; Łojkowski, W.; Kostrzewa-Janicka, J.; Mierzwińska-Nastalska, E. Preparation and Characterisation of Poly(methyl metacrylate)-Titanium Dioxide Nanocomposites for Denture Bases. Polymers 2020, 12, 2655. [CrossRef] 
40. Shirkavand, S.; Moslehifard, E. Effect of $\mathrm{TiO}_{2}$ Nanoparticles on Tensile Strength of Dental Acrylic Resins. Dent. Clin. Dent. Prospects 2014, 8, 197-203. [CrossRef]

41. Cheng, Z.L.; Qin, X.X.; Liu, Z.; Qin, D.Z. Electrospinning Preparation and Mechanical Properties of PVA/HNTs Composite Nanofibers. Polym. Adv. Technol. 2017, 28, 768-774. [CrossRef]

42. Huhtamäki, T.; Tian, X.; Korhonen, J.T.; Ras, R.H.A. Surface-Wetting Characterization Using Contact-Angle Measurements. Nat. Protoc. 2018, 13, 1521-1538. [CrossRef]

43. Wei, W.; Abdullayev, E.; Hollister, A.; Mills, D.; Lvov, Y.M. Clay Nanotube/Poly(Methyl Methacrylate) Bone Cement Composites with Sustained Antibiotic Release. Macromol. Mater. Eng. 2012, 297, 645-653. [CrossRef]

44. da Silva Dantas, A.; Lee, K.K.; Raziunaite, I.; Schaefer, K.; Wagener, J.; Yadav, B.; Gow, N.A. Cell Biology of Candida Albicans-Host Interactions. Curr. Opin. Microbiol. 2016, 34, 111-118. [CrossRef]

45. Altarawneh, S.; Bencharit, S.; Mendoza, L.; Curran, A.; Barrow, D.; Barros, S.; Preisser, J.; Loewy, Z.G.; Gendreau, L.; Offenbacher, S. Clinical and Histological Findings of Denture Stomatitis as Related to Intraoral Colonization Patterns of Candida Albicans, Salivary Flow, and Dry Mouth. J. Prosthodont. 2013, 22, 13-22. [CrossRef] [PubMed]

46. Yoshijima, Y.; Murakami, K.; Kayama, S.; Liu, D.; Hirota, K.; Ichikawa, T.; Miyake, Y. Effect of Substrate Surface Hydrophobicity on the Adherence of Yeast and Hyphal Candida. Mycoses 2010, 53, 221-226. [CrossRef] [PubMed]

47. Cannon, R.D.; Chaffin, W.L. Oral Colonization by Candida Albicans. Oral Biol. Med. 1999, 10, 359-383. [CrossRef] [PubMed]

48. De Matteis, V.; Cascione, M.; Toma, C.C.; Leporatti, S. Morphomechanical and Organelle Perturbation Induced by Silver Nanoparticle Exposure. J. Nanopart. Res. 2018, 20, 273. [CrossRef]

49. Vandebriel, R.J.; de Jong, W.H. A Review on Mammalian Toxicity of ZnO Nanoparticles. Sci. Appl. 2012, 5, 61-71. [CrossRef] [PubMed]

50. Attarilar, S.; Yang, J.; Ebrahimi, M.; Wang, Q.; Liu, J.; Tang, Y.; Yang, J. The Toxicity Phenomenon and the Related Occurrence in Metal and Metal Oxide Nanoparticles: A Brief Review From the Biomedical Perspective. Front. Bioeng. Biotechnol. 2020, 8, 822. [CrossRef]

51. Naz, S.; Gul, A.; Zia, M. Toxicity of Copper Oxide Nanoparticles: A Review Study. IET Nanobiotechnol. 2020, 14, 1-13. [CrossRef] 